\title{
Development of Creative Potential with RSSAA Students at the Course "Electronic and Computer Music"
}

\author{
Sergei Filatov-Beckmann \\ Russian State Specialized Arts Academy \\ Moscow State Tchairovsky's Conservatory \\ Moscow, Russia \\ e-mail: mserg1958@mail.ru
}

\begin{abstract}
This article offers some examples of electronic computer music, created by RSSAA students on the basis of computer technologies. The necessity of this technology is the development of the student's potential. Innovation is in the teaching of blind musicians.
\end{abstract}

Keywords-mathematic music; music-acoustic model; computer-music theology

\section{INTRODUCTION}

One of the modern directions of music art is the creation of electric-acoustic music. The specter of electric-acoustic music of our time includes music generated by both electronic and computer means. A great role in its creation belongs to a composer's line with great names: Xenakis and Lutoslavsky, Ligeti and Denisov, Pusser, Berio, Pendretsky, Shnitke, Gubaidulina and many others - who created a pantheon of the brightest compositions of modern music.

In a number of compositions a computer becomes a kind of music co-author of the composer. In this case, we're discussing the so-called algorithmic music. This kind of music represents an acoustic result of a certain algorithm realization. Ya. Xenakis is the author of the idea of the usage of the basis of relativity and games theory [11]. One of the first creators of such music algorithms in Russia was an unknown mathematician and musician, R. Zaripov [12].

\section{ABOUT THE METHODS OF CREATION OF COMPUTER MUSIC}

How is a simple computer algorithm created? It may be produced as a kind of "unchanged" construction, which management is limited only by the speed of reproduction and an opportunity of "changing" of performed elements. Such construction represents a limited space for the creative fantasy of the composer.

There is a much more complex algorithm, allowing an opportunity for the processing of a computer sound line by a composer. In this case we should talk about a computer algorithmic interactive music $[1,11]$. Yet, in the basis of the machine algorithm there may be another - a rather hardly determined process. Such process defines the generation and evolution of a phenomenon, called "mathematical music". It is created on the basis of authorized computer music acoustic model MARC $[4,5]$.

As a rule, a computer model is aimed at a solution of particular equations, describing different dynamic processes. Such processes may have different origins (biologic, physical, chemical) and are also capable of reflecting different human activity spheres (a social one, an economic one, a historic one). The author has chosen an area, connected to a number of geophysical processes.

An algorithm of acoustic soundings construction includes the forming of different elements of numerical multitude as a numerical experiment on the basis of the model MARC $[4,5]$. In accordance with this, an element is the height of a sound. For the realization of such an operation a special original converter program is developed. In a simple case; a temp, a tone and a volume of such computer sounding is per-fixed and does not change in time. Thus, only the height of music is changed. Still, its variety causes mono-voice electronic sound line.

The music editing programmed application represents wide opportunities for music-acoustic experiments. Thus, a mono-voice sound line in MIDI format is sub-divided into several parts, located in different tracks, which results in polyphonic sounding and volume variations. Its transformation into a wave format allows access to a wide palette of sound effects, contained in the menu of music editing programs. Application of one or several effects allows changing of the tissue [13]. For instance, application of "multiple reflection" gives an opportunity to form the whole row of the so-called sonar sounding: from the colorful harmony to the developed sonority, which determines only the sounding registers (and not the extreme sounds) [1].

An authorized music-static model MQS allows analysis of the specifics of the received sounding on the basis of certain principles of non-linear dynamics and mathematical 
statistics (reflections reconstruction, correlation measurement calculation, noises quantum evaluation, etc.). Such data is unavailable for common traditional music analysis and may be fixed only on the basis of computer research.

Thus, we receive a technological line, consisting of the number multiplicity generation, and transformation of the received numbers into sounds and computer analysis of sounding. Such line is considered as computer musical modeling [8]. Let us notice that all mono sound music examples have very pure computer origin, the students create Polyphony in the result of creative students` verification of the mono-sound examples.

Transfiguration of the results of numeral integration into a music midi-file is provided on the basis of the authorized computer program (Cybercom converter) [10].

In a number of works $[7,8,10]$ we have represented in detail the principles of model construction MARC and MQS; analysis of a number of "mathematical music" examples is being made, which has been created by RSSAA students with a teacher's help. Based on all the above mentioned, we determine mathematical music as computer-algorithmic, interactive and determined. Its interactivity follows from the algorithm optimization chance; its determinism is expressed in the fact that every note has its own number, which is a result of numeric integration in the space-time continuum.

Sound examples represent an important and original component of the sound-producers' education. The specifics of these kinds of students studying at RSSAA are that many of them have physical or sensor limitations, in particular, eyesight or hearing limitations.

Working with a mass of computer soundings causes a great interest with the students. It concerns first of all sound producers: before entering a college they seldom have enough theoretic and music preparation. Academic classes on music theory subjects are added by mono-sound line processing, which are turned into polyphonic examples of "mathematical music". Such a process is based upon a multiple tested authorized computer-music technology.

Mono-sound line consists, as a rule, of a number of different elements, possessing enough contrast character "Fig. 1". This, specifically in regards to mono line, is a reflection of the specifics of physical processes and is incorporated in music interpretation.

The students, with the help of a teacher, divide mono sound line into a random number of fragments. For example, a music-editing program allows the 'vertical' placement of fragments, imitation construction, and also the movement of these fragments from one and other. Such combinations allow the creation of polyphonic music tissue, covering the scope of 8-9 octaves. At the same time the technique of multi voice tissue includes the following:

- increase and decrease of the voices;
- voices combination on imitation polyphony principle of the vertical cluster presentation, combination of multiple voices with mono voices, simultaneous and consecutive voices appearance;

- application of different tissues in the same examples (grand-piano, an organ, string, brass, tubes, bells);

- wide application of computer acoustic effects, allowing to get some bright, unusual even exotic sounds.
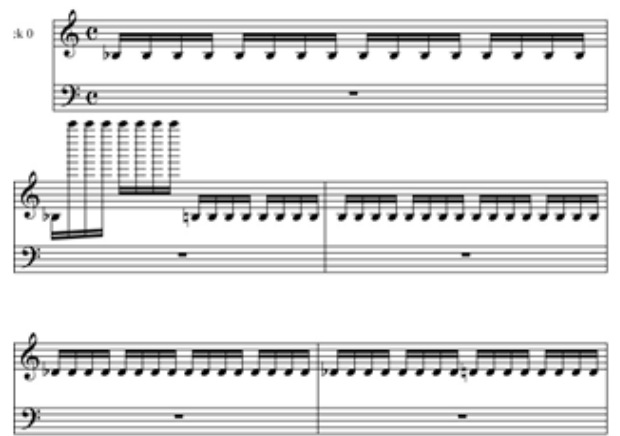

Fig. 1. A model of mono-sound computer-sound line

The fragment consists of a number of sections, containing obstinate repeated sounds of the middle register. These sections slowly rise, covering a three-tone scale. The higher contrast is a sudden "expression" of several sounds into four octaves with return to the middle register.

The processed fragments represent different kinds of multi-sound tissue. One of them contains an effect of slow growth of the number of voices from one to seven-eight. Since the entering voices are similar on the sound combination and obstinate-rhythmic repetition (a number of fragments of the same initial sound line is used), the presentation character is associated with imitationpolyphony method of inclusion of a growing number of voices up to the cluster sounding "Fig. 2".

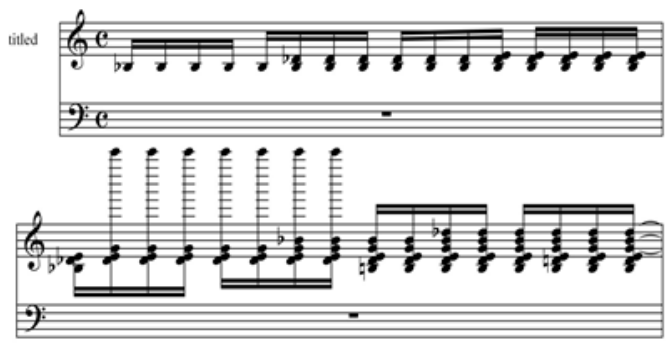

Fig.2. By-turn voice entering

The following example demonstrates an unchanged texture of vertical sound combinations at almost complete polyphony keeping and the lower and middle registries scales, reminding of a choral-harmony construction of the tissue "Fig. 2". 


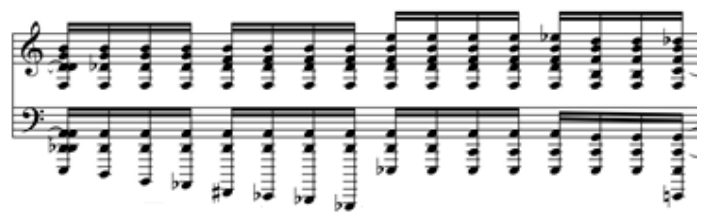

Fig. 3. Choral-tissue presentation

Let us consider another example of a mono-voice sound line, contrasting with example 1 (as a result of the length of this line we don't offer its linear processing's). Let us remark a wide sound scale, covering several octaves and also a variety of octaves as well as a variety of the "motives", combining this line "Fig. 4".

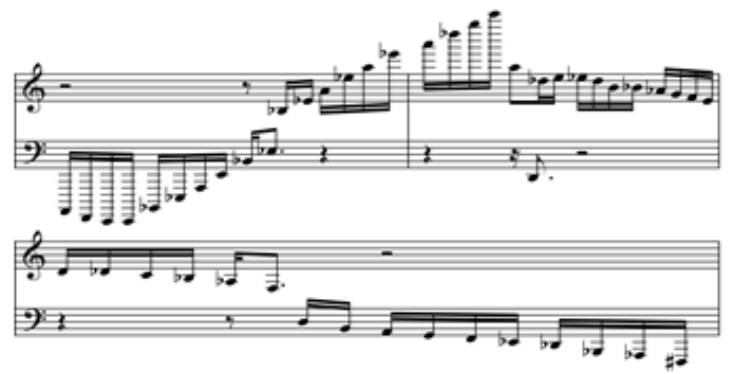

Fig.4. Mono-sound computer-generated line of a wide scale

In the following example an imitation rising movement is represented, built upon the obstinate repetition of cluster combinations and the height variations "Fig. 5".

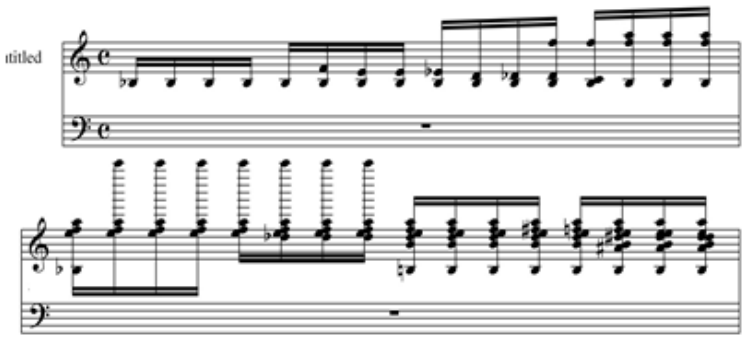

Fig.5. Cluster structures Appearance

What is a scientific-pedagogical aspect of the synthesis of mathematical music as a result of two areas interaction a music science and computer modeling? As mentioned above, student-musicians and music sound producers, in work with whom the author is involved, in many cases suffer serious eyesight problems (part $r$ complete eye sight deprivation). That is why, as a long pedagogical practice showed, many students orient with great interest in the area of professional computer composition. Mathematical music examples become for them a "construction material" for their own compositions, which stimulates socialization process and contributes to the creative potential development with the students.

Since 2008 we've been developing a computer music examples bank, created by the students. At present, a number of student's interpretations of the basic variations of mathematical music are so convincing that the created bank is constantly renovated.

\section{CONCLUSION}

We should remark that music files noting is as a rule the result of the students' computer composition creativity. Thus, computer music technology allows the students to test their abilities in computer modeling areas and in the area of music composition, which contributes to the development of creative process.

\section{REFERENCES}

[1] Modern Composition Theory. Manual. Moscow, Music, 2005.

[2] Tichonov V.N., Samarsky A.A. Mathematical Physics Equations. Manual. Moscow, MSU, 1999.

[3] Filatov-Beckmann S.A. As mathematical music is born: pedagogical aspects. Scientific almonach. Chebocksary, Pedagogics and Psychology Scientific Institute. 2003, 2-nd edition, pp. 10-15.

[4] Filatov-Beckmann S.A. Methematical-music modeling and parameters of order. Information technologies in Science and Education. Scientific articles Review. Saint-Petersburg, Russian State Herzen Pegagodical University, 2005, pp.235-240.

[5] Filatov-Beckmann S.A. Computer-music modeling as an instrument of music information research. Symbols, codes, signs. Materials collection of the 10th conference Grigorian readings. Moscow, Muscow Humanitarian University Publishing House. 2008, pp.134 140 .

[6] Filatov-Beckmann S.A. On the idea of multidimentionality of a composition and computer music analysis methods. Music Studies, №3, 2008. Nauchtechlitizdat Publishing House, 2008, pp. 2-5.

[7] Filatov-Beckmann S.A. Introduction to Computer Music Modeling. (part 1). Society Scientific Magazine. 2014. № 2. pp.40-45.

[8] Filatov-Beckmann S.A. Introduction to Computer Music Modeling: some pedagogical aspects. LAP LAMBERT Academic Publishing Saarbrucken Deutschland - 2014. - 120 p.

[9] Filatov-Beckmann S.A. Introduction to Computer Music Modeling: (part 2) Society Scientific Magazine №3-4, 2014, pp.63-68.

[10] Filatov-Beckmann S.A. Introduction to Computer Music Modeling. Society Scientific Magazine -2015 №1. pp.75-81.

[11] Xenakis I. Formalized Music, thoughts and mathematics in composition. Indiana University Press, Bloomington, 1972.

[12] Zaripov R.H. Music and Cybernetics. Moscow, Science, 1971.

[13] Zoller S. A. Computer Music Creation: from the simplest to the difficult one. Saint Petersburg, 2005. 320 pp. Illustrated. 